\title{
Influence of multiple pre-injection on engine performance based on exhaust gas control
}

\author{
Enxing Zhang ${ }^{1, *}$, Tengteng $\mathrm{Li}^{1}$, Zenghui $\mathrm{Yin}^{1}$, Guotian $\mathrm{Li}^{1}$, Jing $\mathrm{Hao}^{1}$, and Zhengran $\mathrm{Yu}^{2}$ \\ ${ }^{1}$ China Automotive Technology \& Research Center Co. Ltd, China \\ ${ }^{2}$ Dalian University of Technology, China
}

Keywords: EGR, pre-injection, NOx, emission.

\begin{abstract}
With the development of the society, the emission laws are increasingly strict, and EGR and multiple pre-injection strategy can effectively reduce emissions. In order to study the influence of EGR rate and pre-injection on the emission and performance of engine, a computational fluid dynamics (CFD) simulation model was established based on GT power. By changing the EGR rate, the number of preinjection and the amount of pre-injection, the best technology coupling point is explored. The results show that EGR can effectively reduce the generation of NOx, but it will lead to the increase of soot production and the decrease of power; pre-injection can improve the trade-off relationship between NOx and power.
\end{abstract}

\section{Introduction}

Because of the high efficiency and fuel economy of diesel engine, it has been used as power source by vehicle and non-road machinery. Due to inadequate fuel-air mixing of combustion characteristics, the PM and NOx emissions of the diesel engine are high. Continuous stringent emission regulations require significant reductions in NOx related emissions. EGR technology is known to be the most effective technology to reduce NOx, but it can lead to more soot. ${ }^{[1]}$. The relationship between NOx and power is improved by pre-spraying strategy ${ }^{[2]}$. The combination of in-cylinder technology and post-processing system can effectively control emissions and reduce the burden of post-processing system.

EGR can reduce NOx by changing the gas composition in the cylinder ${ }^{[3]} \mathrm{As}$ the EGR rate increases, the oxygen concentration in the cylinder decreases, while the concentration of carbon dioxide and water vapor increases. The heat capacity of carbon dioxide and water is higher than that of oxygen, which can effectively reduce the temperature in the cylinder. According to the NOx formation mechanism, lower temperature leads to less NOx formation. However, due to incomplete combustion of diesel oil, soot and BSFC will increase. Pre-injection before the main injection can achieve secondary combustion and improve the combustion environment in the cylinder, so the soot can be reduced.

A large number of scholars have a lot of research on exhaust gas circulation and fuel injection strategy. Youngsoo Park etc. ${ }^{[4]}$ has carried on the correlation experiment to the

* Corresponding author: zhangenxing@catarc.ac.cn 
high pressure EGR and the low pressure EGR on the marine engine. The results showed that the NOx decreased significantly, while the BSFC and soot increased significantly. Roel etc. ${ }^{[5]}$ conducted experiments on EGR in marine diesel engines. The results show that with the increase of EGR rate, NOx emissions will decrease, while CO and soot will decrease. The relationship between EGR and soot limits the application of EGR. Fuel injection strategy can help improve this relationship. When NOx emissions decrease as EGR increases, soot increases more slowly than before. Jinwoo Lee etc. ${ }^{[6]}$ studied the changes in engine performance of heavy-duty diesel engines between single pre-injection and double pre-injection, and used heat release analysis, flame combustion analysis and emission performance analysis to study the engine. The research results show that during a single pre-injection, the engine's emissions related to NOx and soot are effectively reduced, but the HC-related pollutants are increasing significantly. During double pre-injections, NOx and soot are reduced relative to a single pre-injection of the engine, and are accompanied by a reduction of more than half of $\mathrm{HC}$ emissions.

\section{Model establishment and calibration}

This model is based on a five-cylinder low-speed two-stroke marine engine. Table 1 below shows the specific parameters of the engine.

Table 1. Specific engine parameters.

\begin{tabular}{cc}
\hline Parameters & Value \\
\hline bore $\times$ stroke $(\mathrm{mm})$ & $520 \times 2315$ \\
Compression ratio & $24.91: 1$ \\
Power $(\mathrm{kW})$ & 6408 \\
Speed $(\mathrm{rpm})$ & 99 \\
& $2.13^{\circ} \mathrm{CA}$ ATDC \\
Crank angle at the start of injection & $9.88^{\circ} \mathrm{CA}$ ATDC \\
Crank angle at the end of injection & 36.998 \\
Fuel injection (g/cycle) &
\end{tabular}

Table 2. Calibration data.

\begin{tabular}{cccc}
\hline & Actual & Analog values & Deviation \\
\hline Compression pressure & 158 & 161.7 & $+2.3 \%$ \\
Combustion burst pressure & 145.4 & 146.5 & $+0.75 \%$ \\
Power & 6408 & 6101 & $-4.7 \%$ \\
\hline
\end{tabular}

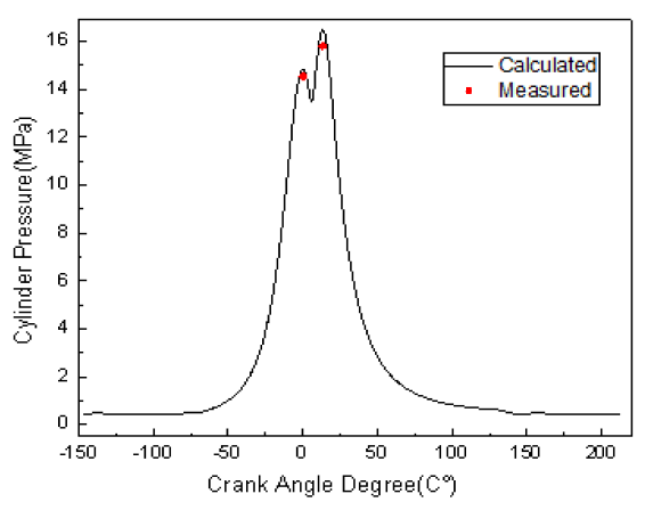

Fig. 1. Calibration of pressure in the cylinder. 
The model mainly studies the emission-related performance of marine engines. The main research conditions in this paper are $100 \%$ load conditions of the engine, and its speed is $99 \mathrm{r} / \mathrm{min}$. Since there are only two points in the actual pressure curve (compression pressure and combustion burst pressure) in the relevant test data, the deviation between the simulated pressure and the test pressure is $2.6 \%$, and the simulation power is $4.7 \%$ lower than the test power. The pressure and power deviations of the calculated and experimental values are within the allowable range of the engineering calculation simulation.

GT-Power software is used for simulation calculation in this paper, using EngCylCombDIJet as D quasi-3 predicted combustion model. The Nagle and SticklandConstable models are used to predict NOx emissions; the EngCylNO model is used to predict soot; the WoschniGT heat transfer model is used to simulate heat dissipation and heat transfer in the cylinder. The model can accurately predict the variation of heat transfer parameters of emission parameters. The model controls the EGR rate by introducing the exhaust gas into the intake manifold after the intake air cooler. Since the exhaust pressure is less than the intake pressure, the exhaust is introduced into the intake manifold by mechanical turbocharging. The exhaust volume is controlled by controlling the speed of the mechanical turbine. To keep the air input constant, a variable diameter tee is provided between the intercooler and the supercharger ${ }^{[7,8]}$.

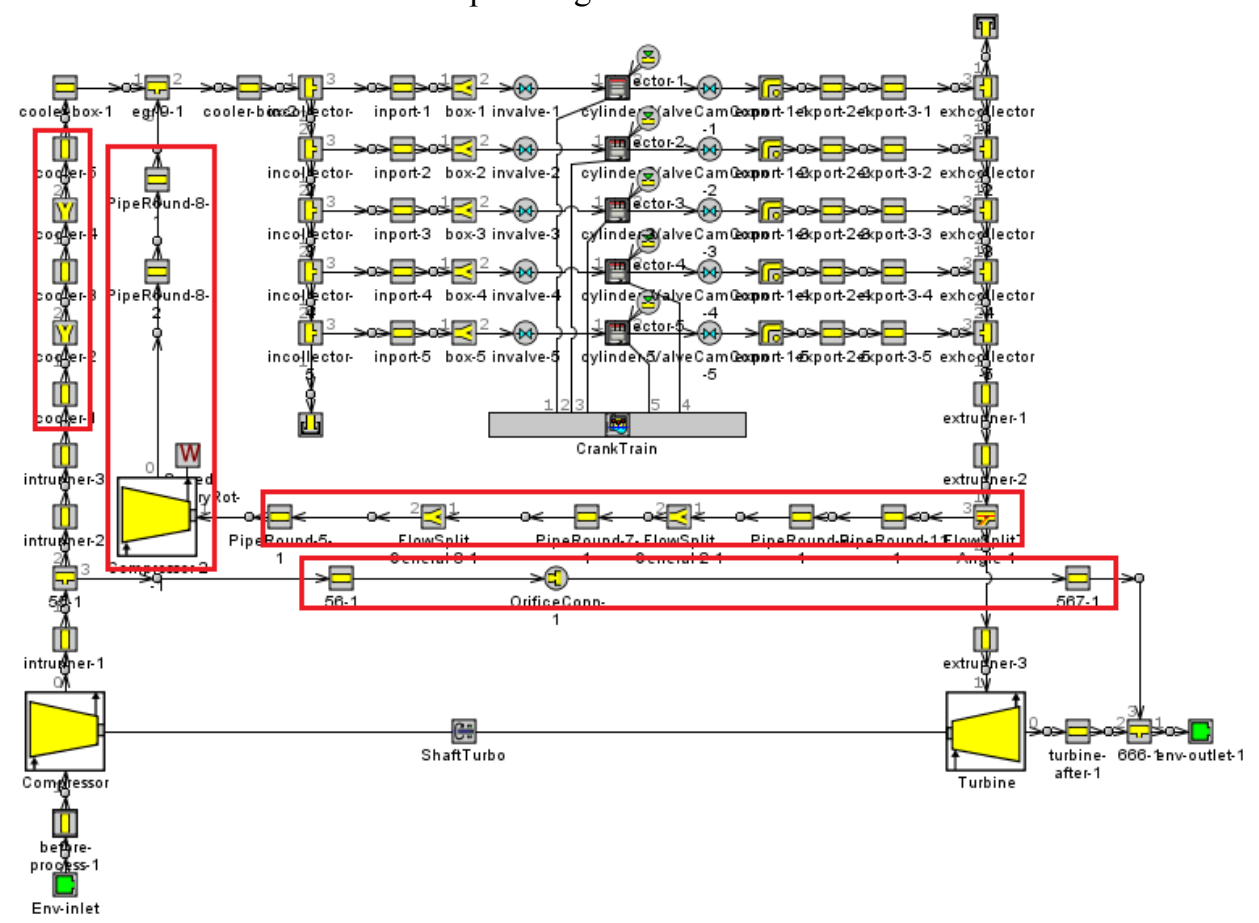

Fig. 2. Engine model diagram.

\section{Effect of exhaust gas control on engine performance}

EGR rate usually refers to the ratio of the mass of the exhaust gas entering the cylinder to the total mass of the mixture entering the cylinder. The relevant formulas are shown as formula 1 . In the model of this paper, the total intake volume of the cylinder remains constant. Since the pressure of the exhaust is less than the pressure of the intake, the model requires a mechanical turbine to deliver the exhaust gas before the intake manifold. The 
amount of intake air is controlled by the speed of the mechanical turbine. As the total intake volume of the cylinder remains constant, it is necessary to bypass in front of the intercooler to deliver excess fresh air to the exhaust turbine.

$$
\phi_{E G R}=\frac{\mathrm{m}_{\mathrm{EGR}}}{m_{A I R}+m_{E G R}}
$$

In the formula, $\Phi_{\mathrm{EGR}}$ is EGR rate; $\mathrm{m}_{E G R}$ is the quality of the exhaust gas entering the cylinder per cycle; $\mathrm{m}_{A I R}$ is the quality of fresh gas entering the cylinder per cycle.

In the simulation calculation, the EGR rate increased from 5\% to $40 \%$. Figure 3 shows the relationship between NOx and soot. When the EGR rate is less than $15 \%$, the NOx decreases less and the soot fluctuation is small. At low EGR rate, the oxygen concentration changes less. Therefore, the combustion deterioration in the cylinder is not serious, and the temperature change is small, resulting in a slower reduction in NOx and soot emissions. When the EGR rate is greater than $15 \%$, the NOx decreases linearly with the increase of the EGR rate, and the soot rises rapidly. The higher the EGR rate is, the faster the soot grows. At high EGR rate, the combustion process in the cylinder deteriorates seriously and the combustion temperature decreases rapidly. Therefore, at the same time as the rapid decrease of NOx, the rate of decrease of soot is particularly obvious.

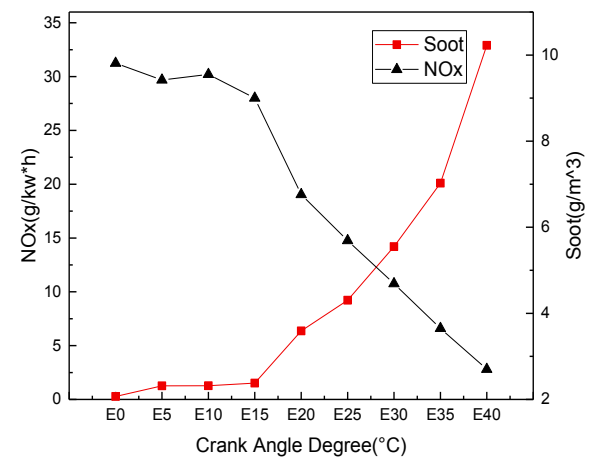

Fig. 3. Relationship between NOx and soot with EGR rate.

Figure 4 shows the variation of cylinder temperature at different EGR rates. As the EGR rate increases, the carbon dioxide and water vapor with higher specific heat capacity in the cylinder will also increase. The increase in the specific heat capacity of the mixed gas in the cylinder causes the temperature in the cylinder to decrease, and the formation of NOx decreases sharply. Some oxygen molecules in the fresh air are replaced by carbon dioxide molecules and water vapor, thereby reducing the local combustion rate and temperature. The increased carbon dioxide and water vapor directly affect combustion and inhibit NOx formation.

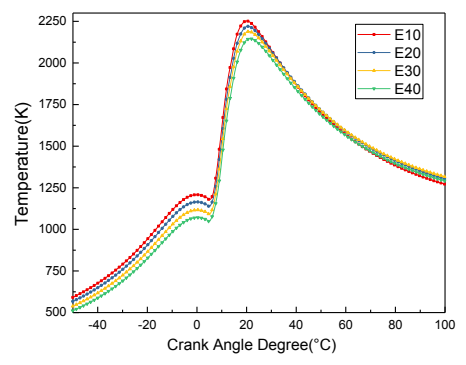


Fig. 4. Cylinder temperature changes with crank angle at different EGR rates.

\section{Influence of single pre-injection coupled with exhaust gas circulation on engine performance}

Before the start of main injection, a pre-injection is completed. Under different EGR rates, change the amount of pre-injection and the angle of pre-injection to achieve the change in combustion in the cylinder, so as to obtain better emission performance and economic performance. Based on the EGR rate of $10 \%, 20 \%, 30 \%$, a single pre-injection is completed under the condition of a certain total fuel injection amount. The pre-injection interval angle is defined as the interval between the pre-injection start time and the main injection start time. Under different EGR rates, the pre-injection quantity and pre-injection interval angle are constantly changing. During this change, the NOx is also constantly changing. Therefore, it is made into a MAP format to explore the effect of pre-injection technology on engine emissions at different EGR rates. The purpose is to explore the effect of the coupling of the two technologies on the emission reduction, and to find the best emission point in the MAP.

When the EGR rate is $10 \%$, the change trend of NOx with the pre-injection amount and the pre-injection interval angle is shown in figure 5. At the EGR rate of $10 \%$, the initial NOx is $17.92 \mathrm{~g} /(\mathrm{kW} \mathrm{h})$. When the pre-injection volume occupies $15 \%$ of the total oil volume and the interval angle is $10^{\circ}$, the NOx in the MAP diagram reaches the lowest value of $15.64 \mathrm{~g} /(\mathrm{kW} \cdot \mathrm{h})$, which reduces the NOx by $12.72 \%$. With the increase of the interval angle, NOx shows the trend of first decreasing and then decreasing; with the increase of fuel injection amount, NOx showed an increasing trend. This is because the temperature decreases first and then rises as the pre-inject interval angle increases, resulting in the NOx change trend as shown in figure 5 .

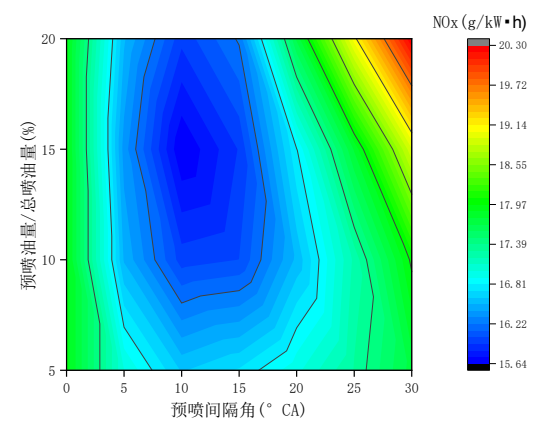

Fig. 4. The change trend of NOx with pre-injection quantity and pre-injection interval angle at the EGR rate of $10 \%$.

As shown in Figure 6, when the EGR rate is $20 \%$, the initial NOx value is $12.29 \mathrm{~g} /(\mathrm{kW} \cdot \mathrm{h})$. When the pre-injection volume occupies $10 \%$ of the total oil volume and the interval angle is $10^{\circ}$, the NOx reaches the lowest value of $11.46 \mathrm{~g} /(\mathrm{kW} \cdot \mathrm{h})$, which reduces the NOx by $6.75 \%$. As the pre-injection interval angle and the amount of preinjection increase, NOx begins to increase.

When the EGR rate is $30 \%$, due to the large amount of pre-inject, the amount of oxygen in the cylinder is insufficient and the combustion deteriorates sharply. So in figure 7, the pre-inject volume is set to a maximum of $15 \%$. When the EGR rate is $30 \%$, the initial NOx value is $7.4 \mathrm{~g} /(\mathrm{kW} \cdot \mathrm{h})$. When the pre-injection volume occupies $5 \%$ of the total oil volume and the interval angle is $10^{\circ}$, NOx reaches the minimum value of $6.9 \mathrm{~g} /(\mathrm{kW} \cdot \mathrm{h})$, which 
reduces NOx by $6.76 \%$. The overall NOx change trend is the smallest in the lower left corner and the largest in the upper right corner. This is because the larger the pre-injection interval angle, the more sufficient the combustion, the higher the in-cylinder temperature, and the more NOx is generated. The more the pre-injection quantity, the more heat generated by the pre-injection, the higher the in-cylinder temperature, the more NOx produced.

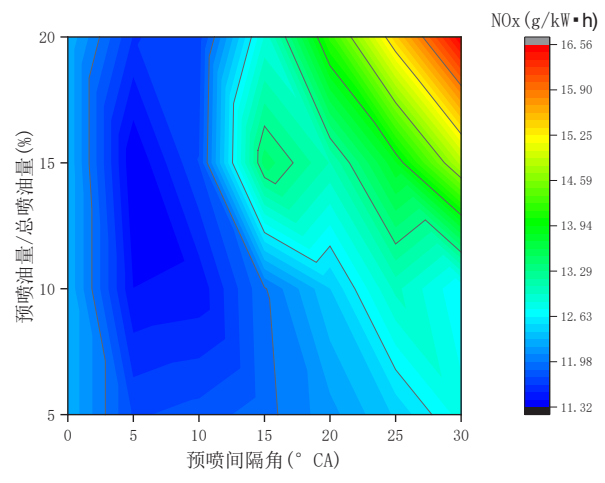

Fig. 6. The change trend of NOx with pre-injection quantity and pre-injection interval angle at the EGR rate of $20 \%$.

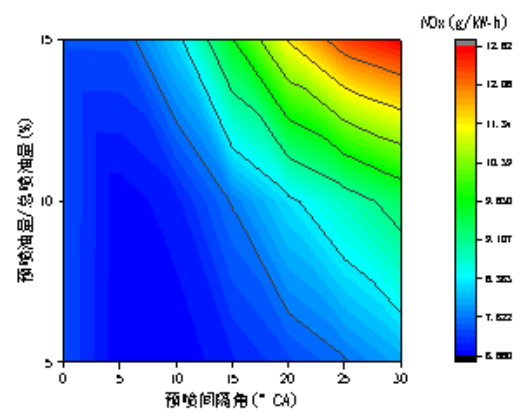

Fig. 7. The change trend of NOx with pre-injection quantity and pre-injection interval angle at the EGR rate of $30 \%$.

\section{Effect of double pre-inject coupled with exhaust gas cycle on engine performance}

Double pre-spraying is completed before the main injection starts. When the EGR rate is different, the pre-injection quantity and pre-injection interval angle parameters are changed. Based on the EGR rate of $10 \%, 20 \%, 30 \%$, the injection amount of each cycle is constant. The pre-injection quantity is divided into two average injections within the injection interval angle. The pre-inject interval angle is defined as the interval angle from the start time of the first pre-inject to the start time of the main inject. That is, the interval angle from the second injection start time to the main injection start time is half of the preinjection interval angle.

At the EGR rate of $10 \%$, NOx presents a trend of low in the middle and high around in the MAP diagram. When the pre-injection volume occupies $15 \%$ of the total oil volume and the interval angle is $15^{\circ}$, NOx reaches the lowest value of $15.69 \mathrm{~g} /(\mathrm{kW} \cdot \mathrm{h})$. When EGR is $10 \%$, the initial value of NOx is $17.92 \mathrm{~g} /(\mathrm{kW} \cdot \mathrm{h})$, and the MAP map shows a $12.44 \%$ reduction in NOx emissions. With the increase of the pre-inject interval angle, the overall 
change trend of NOx showed a decrease first and then increase. The two consecutive injections at the beginning are superimposed on each other, resulting in a large heat release rate, so NOx is generated at a small interval; as the interval increases, the interference gradually decreases, and the NOx generation gradually decreases. The further expansion of the separation angle enables the fuel to be fully burned, and the temperature in the cylinder is high, which makes the NOx emissions high.

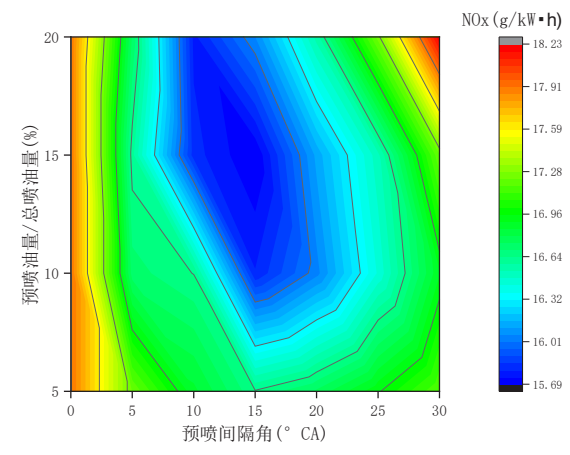

Fig. 8. The change trend of NOx with pre-injection quantity and pre-injection interval angle at the EGR rate of $10 \%$.

As shown in Figure 9, when the EGR rate is $20 \%$, the initial NOx value is $12.29 \mathrm{~g} /(\mathrm{kW} \cdot \mathrm{h})$. When the pre-injection amount occupies $10 \%$ of the total oil amount and the interval angle is $10^{\circ}$, the NOx reaches the lowest value of $11.25 \mathrm{~g} /(\mathrm{kW} \cdot \mathrm{h})$, which reduces the NOx by $8.46 \%$. The overall change trend of the NOx is similar to that of the EGR rate of $10 \%$. With the increase of the interval angle of the pre-spray, the NOx increases first and then decreases. With the increase of the amount of the pre-spray oil, the NOx increases.

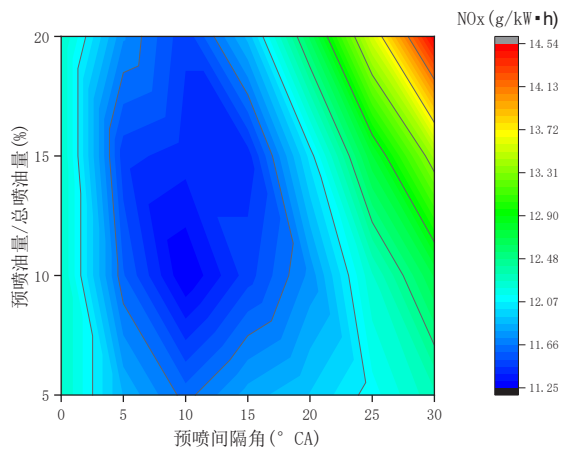

Fig. 9. The change trend of NOx with pre-injection quantity and pre-injection interval angle at the EGR rate of $20 \%$.

As shown in Figure 10, when the EGR rate is $30 \%$, the initial NOx value is $7.4 \mathrm{~g} /(\mathrm{kW}$ -h). When the pre-injection amount occupies $5 \%$ of the total oil amount and the interval angle is $10^{\circ}$, NOx reaches the lowest value of $6.87 \mathrm{~g} /(\mathrm{kW} \cdot \mathrm{h})$, which achieves a reduction of NOx by $7.16 \%$. The overall change trend is similar to the above two figures, but the change range is reduced. As the pre-injection volume increases, it also shows an increasing trend. 


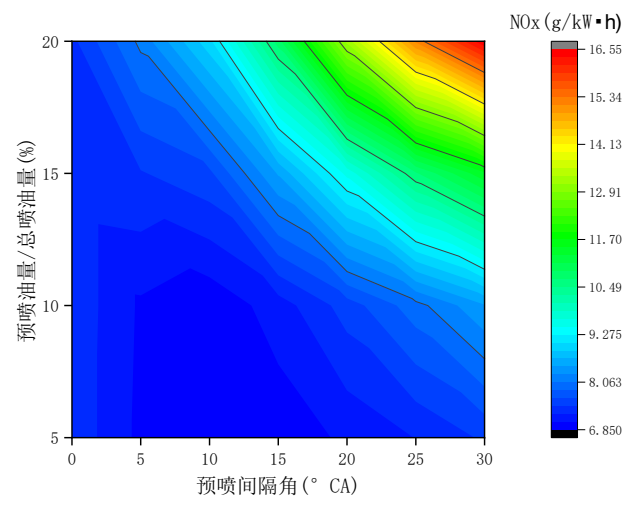

Fig. 10. The change trend of NOx with pre-injection quantity and pre-injection interval angle at the EGR rate of $30 \%$.

\section{Effect of four pre-injection coupled with exhaust gas cycles on engine performance}

When the EGR rate is set at $10 \%$, NOx the parameters change with the pre-injection amount and the pre-injection interval angle as shown in figure 11. At the EGR rate of $10 \%$, NOx value is $17.92 \mathrm{~g} /(\mathrm{kW} \cdot \mathrm{h})$, When the pre-injection amount exceeds the total oil amount by $15 \%$ and the interval angle is $20^{\circ}$, the NOx in the MAP diagram reaches the lowest value of $15.62 \mathrm{~g} /(\mathrm{kW} \cdot \mathrm{h})$, which reduces the NOx by $12.83 \%$. With the increase of the interval angle, NOx shows the trend of first decreasing and then rising; With the increase of fuel injection, NOx showed an upward trend. This is because the temperature decreases first and then rises with the increase of the pre-inject interval angle.

When the EGR rate is set at $20 \%$, NOx the parameters change with the pre-injection amount and the pre-injection interval angle as shown in figure 12. At the EGR rate of $20 \%$, NOx value is $12.29 \mathrm{~g} /(\mathrm{kW} \cdot \mathrm{h})$, When the pre-injection volume occupies $15 \%$ of the total oil volume and the interval angle is $10^{\circ}$, the NOx in the MAP diagram reaches the lowest value of $11.31 \mathrm{~g} /(\mathrm{kW} \cdot \mathrm{h})$, which reduces the NOx by $7.97 \%$. The overall change trend is similar to the EGR rate of $10 \%$.

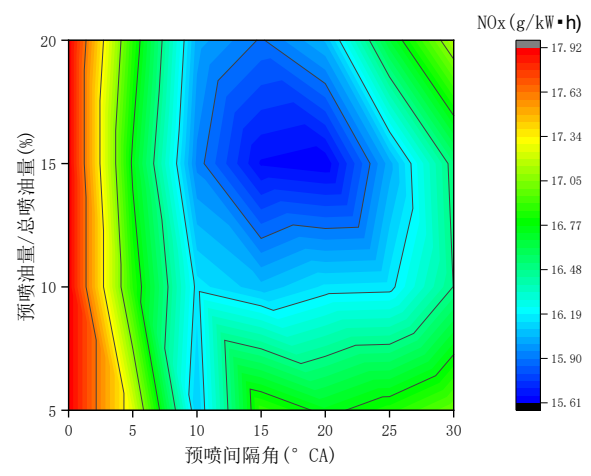

Fig. 11. The change trend of NOx with pre-injection quantity and pre-injection interval angle at the EGR rate of $10 \%$. 


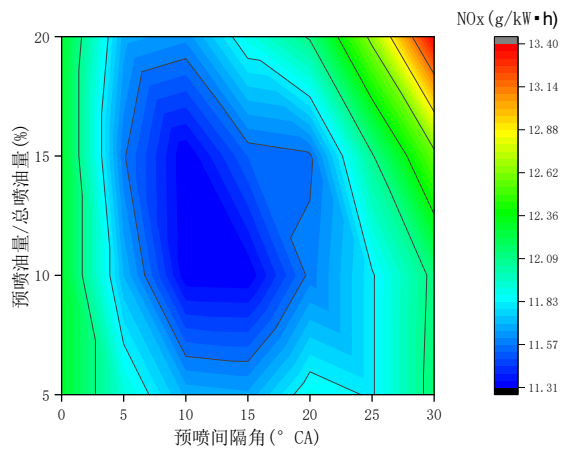

Fig. 12. The change trend of NOx with pre-injection quantity and pre-injection interval angle at the EGR rate of $20 \%$.

When the EGR rate is set to $30 \%$, the NOx changes with the parameters of the preinjection amount and pre-injection interval angle as shown in Figure 13. When the preinjection amount occupies $10 \%$ of the total oil amount and the interval angle is $10^{\circ}$, the NOx in the MAP diagram reaches the lowest value of $6.9 \mathrm{~g} /(\mathrm{kW} \bullet \mathrm{h})$, which reduces the NOx by $6.76 \%$. The overall change trend is also that as the interval angle increases, NOx increases first and then decreases. As the amount of pre-injection increases, it always increases. But the range of change is smaller than the lower EGR rate.

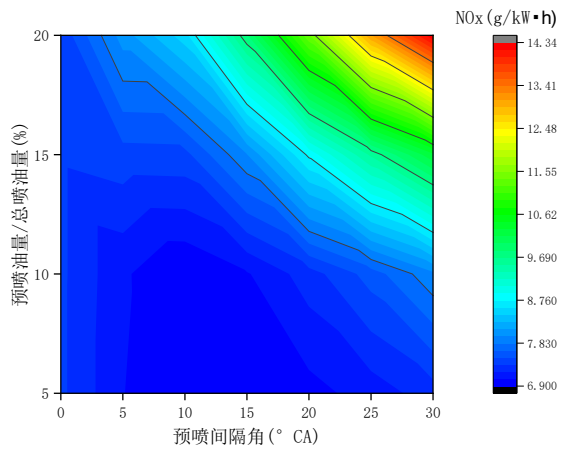

Fig. 13. The change trend of NOx with pre-injection quantity and pre-injection interval angle at the EGR rate of $30 \%$.

\section{Summary and outlook}

Based on the experimental data and 3D simulation data, this paper builds and verifies the 1D model in the GT-Power. On this basis, each technical module is built to realize the simulation of the actual working conditions. Exhaust gas recycling technology can effectively control the generation of NOx, but will lead to a sharp increase in soot and and a decrease in power. By using pre-inject technology, the NOx can be reduced effectively, and the changes of different pre-inject times are different..

Exhaust gas recycling technology can effectively reduce NOx generation, which can be reduced by $84 \%$ to $2.94 \mathrm{~g} /(\mathrm{kW} \cdot \mathrm{h})$ when the EGR rate is $40 \%$. The soot, however, increased from an initial $0.263 \mathrm{~g} / \mathrm{m}^{3}$ to $18.63 \mathrm{~g} / \mathrm{m}^{3}$. The increase was 70.83 times. The power dropped by $12.34 \%$.

2. When the EGR rate is $10 \%$, a single pre-injection can reduce NOx by $12.72 \%$, double pre-injections can reduce NOx by $12.44 \%$, and four pre-injections can reduce NOx by $12.83 \%$. 
3. When the EGR rate is $20 \%$, a single pre-injection can reduce the NOx by $6.75 \%$, double pre-injections can reduce the NOx by $8.46 \%$, and four pre-injections can reduce the NOx by $7.97 \%$.

4. When the EGR rate is $30 \%$, a single pre-injection can reduce NOx by $6.76 \%$, double pre-injections can reduce NOx by $7.16 \%$, and four pre-injections can reduce NOx by $6.83 \%$.

\section{References}

1. Feng L,Tian J,Long W,et al.Decreasing NOx of a Low-Speed Two-Stroke Marine Diesel Engine by Using In-Cylinder Emission Control Measures[J]. Energies,2016,9(4).

2. Larsen U,Pierobon L,Baldi F,et al.Development of a model for the prediction of the fuel consumption and nitrogen oxides emission trade-off for large ships[J]. Energy,2015,80(1): 545-555.

3. Zhou S,Gao R,Feng Y,et al.Evaluation of Miller cycle and fuel injection direction strategies for low NOx emission in marine two-stroke engine[J]. International Journal of Hydrogen Energy,2017,42(31).

4. Park Y,Bae C.Experimental study on the effects of high/low pressure EGR proportion in a passenger car diesel engine[J]. Applied Energy,2014,133(133): 308-316.

5. Verschaeren R,Schaepdryver W,Serruys T,et al.Experimental study of NO x,reduction on a medium speed heavy duty diesel engine by the application of EGR [J]. Energy,2014,76: 614-621.

6. Jinwoo Lee,Jinwoog Jeon,Jungseo Park,Choongsik Bae.Effect of Multiple Injection Strategies on Emission and Combustion Characteristics in a Single Cylinder DirectInjection Optical Engine.SAE 2009-01-1354

7. Hongjun $\mathrm{Xu}$, Limin Shao, Hanbao Chang. Effect of Multiple Injection Parameters on Emission Performance of Direct Injection Diesel Engine [J].] Small internal combustion engines and motorcycles ,2009.38(4):61-64.[23].

8. Xiong Li. 3D Simulation Study on Multiple Spray Combustion of High Pressure Common Rail Diesel Engine [D].] Hubei: Wuhan University of Technology ,2012. 